\title{
Meridional temperature fluxes in the subtropical eastern North Atlantic
}

\author{
LOTHAR STRAMmA* ${ }^{*}$ and Hans-Jörg ISEMER *
}

(Received 3 April 1985; in revised form 29 August 1985; accepted 9 September 1985)

\begin{abstract}
In a regional study of the eastern North Atlantic Ocean east of $35^{\circ} \mathrm{W}$ between $41^{\circ} \mathrm{N}$ and $8^{\circ} \mathrm{N}$ the mean meridional ocean temperature flux was computed from oceanographic and meteorological measurements using the direct method. In the area of the permanent subtropical gyre between $36^{\circ} \mathrm{N}$ and $22^{\circ} \mathrm{N}$, a southward geostrophic temperature flux dominates. The Ekman temperature flux is weak and changes from a southward flux north of $32^{\circ} \mathrm{N}$ to a northward flux south of $32^{\circ} \mathrm{N}$. In the area of the North Equatorial Current and in the tropics the Ekman temperature flux is comparable in magnitude to the geostrophic temperature flux. Therefore, the total temperature flux changes to a northward direction at $20^{\circ} \mathrm{N}$, where the geostrophic transport is still to the south, and becomes large in the tropics, where both components show northward temperature fluxes. The heat flux divergence for the area investigated leads to an ocean heat gain of $0.19 \mathrm{PW}$.

A comparison of annual mean temperature fluxes with temperature fluxes of east-west CTD sections from the winter half-year shows a small seasonal signal in the geostrophic temperature flux in the subtropical gyre but large differences in the tropics. The seasonal changes for the Ekman temperature fluxes are weak.
\end{abstract}

\section{IN TRODUCTION}

KNOWING the heat transport in the ocean is important in estimating the influence of the ocean on overall heat transport of the earth. The ocean serves as a heat energy reservoir which reduces seasonal variability and transports energy from the tropics to the polar regions. Although many investigations have compared the oceanic and atmospheric components of heat transport, the influence of the ocean on overall heat transport is not completely understood. It is believed that the ocean is responsible for heat transport in the tropics and subtropics, while the atmosphere dominates in the subpolar and polar regions.

Oceanic heat transport can be computed by indirect and direct methods. Two fundamentally different indirect methods exist. The classical method has been to consider air-sea interaction: one computes the difference between heat gain and heat loss at the sea surface and the temporal changes of heat storage in the water column (e.g. LAMB and Bunker, 1980; Hastenrath, 1982). The other indirect method uses incoming and outgoing atmospheric radiation and atmospheric heat transport to derive oceanic heat transport, as was done by VONDER HAAR and OORT (1973) for the northern hemisphere.

\footnotetext{
* Institut für Meereskunde, Düsternbrooker Weg 20, 2300 Kiel 1, F.R.G.

+ Present address: Graduate School of Oceanography, University of Rhode Island, Narragansett, RI 02882 , U.S.A.
} 
They found that between 30 and $35^{\circ} \mathrm{N}$ the ocean transports $47 \%$ of the total heat, the fraction being $1.7 \times 10^{22} \mathrm{cal} \mathrm{y}^{-1}\left(=2.26 \mathrm{PW} ; 1 \mathrm{PW}=10^{15} \mathrm{~W}\right)$. At $20^{\circ} \mathrm{N}$ the oceanic component is at a maximum, $74 \%$. The mean oceanic heat transport for 0 to $70^{\circ} \mathrm{N}$ is $40 \%$ of the total heat transport. The seasonal variability of heat transport was calculated by OORT and VONDER HAAR (1976). In the tropics between 10 and $20^{\circ} \mathrm{N}$, they found great variability in oceanic heat storage, with a maximum in spring and a minimum in late summer. The northward transport of heat energy also shows great variability; it reaches a maximum of 4 to $5 \mathrm{PW}$ in spring and autumn. Near the equator the transport changes direction and is directed towards the winter hemisphere.

For the direct method of calculating oceanic heat transport, the velocity distribution in the ocean must be known. The meridional heat flux, $H$, is given as

$$
H=\iint \rho C_{p} \theta v \mathrm{~d} z \mathrm{~d} x,
$$

where the integration is carried out over depth and longitude (HALL and BRYDEN, 1982). $\rho$ is the density of seawater, $C_{p}$ is the specific heat capacity of seawater at constant pressure and is assumed to be constant, $\theta$ is the potential temperature, $v$ is the northsouth component of the absolute velocity, $z$ is depth, and $x$ is the longitudinal variable. For a section where mass is not conserved, $H$ represents the temperature flux. The temperature flux depends on the temperature scale and here is always calculated in ${ }^{\circ} \mathrm{C}$.

With this direct method, HALL and BRYDEN (1982) computed the northward heat transport in the Atlantic Ocean at $25^{\circ} \mathrm{N}$ to be $1.2 \pm 0.3 \mathrm{PW}$ to the north. Assuming zero net geostrophic transport across the whole Atlantic Ocean at $24^{\circ} 30^{\prime} \mathrm{N}$, they derived a zonally averaged, geostrophic meridional velocity profile by decomposing the velocity into a mean and a deviation from the mean for this section. RoEmmich (1980) also used the direct method to calculate the velocity distribution along two latitudes across the North Atlantic with an inverse calculation formalism. He estimated heat transport to the north as $1.2 \mathrm{PW}$ at $24^{\circ} \mathrm{N}$ and $0.8 \mathrm{PW}$ at $36^{\circ} \mathrm{N}$. An overview of more recent results with direct and indirect methods can be found by BRYAN (1983).

One of the very interesting asymmetries in the air-sea heat fluxes is the east-west asymmetry in the subtropical gyres. Warm northward-flowing western boundary currents give rise to areas of intense heat loss while the southward flow in the east are areas of heat gain by the ocean. In a regional study we compute the meridional temperature flux for the subtropical eastern North Atlantic. Following earlier investigations (SIEDLER and Stramma, 1983; Stramma, 1984a) computations were made for the North Atlantic east of $35^{\circ} \mathrm{W}$ between 8 and $41^{\circ} \mathrm{N}$. Total transport is a combination of Ekman transport and geostrophic transport; they are treated separately before computing the total temperature fluxes. In this paper we investigate the change in temperature flux at different latitudes, compare the temperature flux with the mean geostrophic flow field and with the transatlantic sections made by HALL and BRYDEN (1982), investigate regional changes of the importance of heat transport by Ekman transport and by geostrophic transport, and compute the mean net heat gain of the subtropical eastern North Atlantic.

\section{EKMAN TRANSPORT AND SEA SURFACE TEMPERATURES}

Historic selected ship meteorological observations (ssmo) data were used to calculate Ekman temperature fluxes. We used a climatological data set originally assessed by 


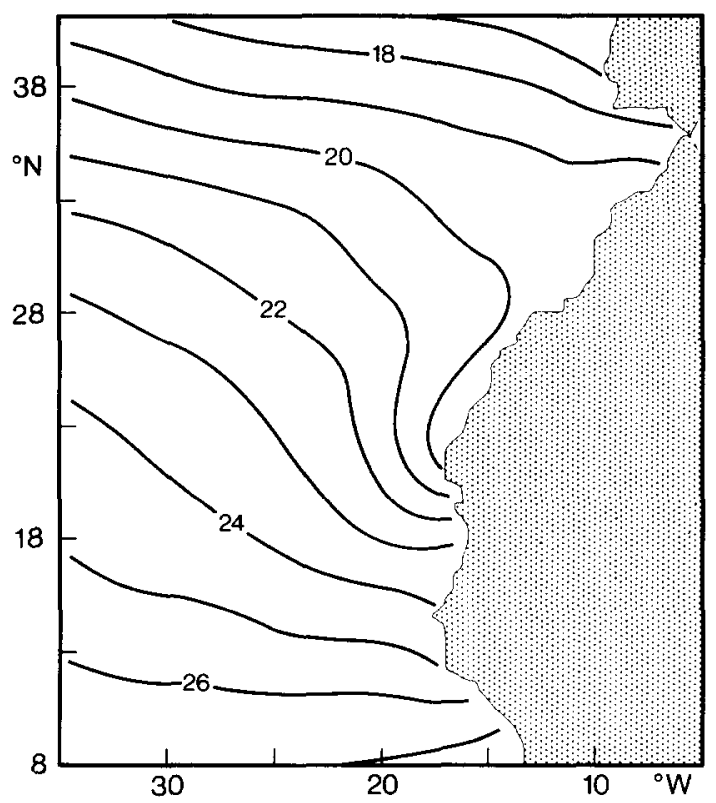

Fig. 1. Mean annual sea surface temperature for 1941 to 1972 . The contour interval is $1^{\circ} \mathrm{C}$.

BUNKER (1976). He presented mean long-term monthly values for irregularly shaped areas in the North Atlantic Ocean for 1941 to 1972.

Using a local, two-dimensional quadratic polynomial method, ISEMER and HASSE (1985) interpolated these data onto a regular $1^{\circ}$ grid net. For the present investigation the monthly fields of both wind stress and sea surface temperature were extracted from this compilation and averaged over areas $3^{\circ}$ in latitude and $3^{\circ}$ in longitude for the temperature flux calculations. The monthly fields were then averaged to obtain the mean annual field. Also air-sea heat fluxes were extracted from BUNKER's (1976) compilation and processed in the same way.

Mean annual sea surface temperature (Fig. 1) has a meridional increase from about $18^{\circ} \mathrm{C}$ at $41^{\circ} \mathrm{N}$ to almost $27^{\circ} \mathrm{C}$ near $8^{\circ} \mathrm{N}$. The nearshore area between about 15 and $30^{\circ} \mathrm{N}$ shows conspicuously lower temperature values due to coastal upwelling. It should be mentioned that monthly means show a distinct annual north-south migration, especially of the nearshore temperatures (see ISEMER and HASSE, 1985). To compute wind stress at the ocean surface, BUNKER (1976) used the well-known bulk equation, with a wind speedand stability-dependent drag coefficient which he estimated from the literature up to that time. Since then, however, marine measurements of turbulent momentum fluxes have been made at various sites in the world's oceans, especially under long fetch conditions (e.g. Hasse et al., 1978; SMITH, 1980), which give lower results for the drag coefficients. A comparison of BUNKER's (1976) parameterization with results of recent measurements is given by SMITH and Dobson (1984) for the OWS (Ocean Weather Ship) Bravo data. A study of the literature available within the last 15 years by one of the authors $(\mathrm{H} .-\mathrm{J}$. ISEMER) found that Bunker's drag coefficient may be too high by $20 \%$. On the other hand, KAUFELD (1981) showed that the Beaufort conversion table which BunKER (1976) used produces too low wind speeds in the range of one to eight Beaufort. This bias may 


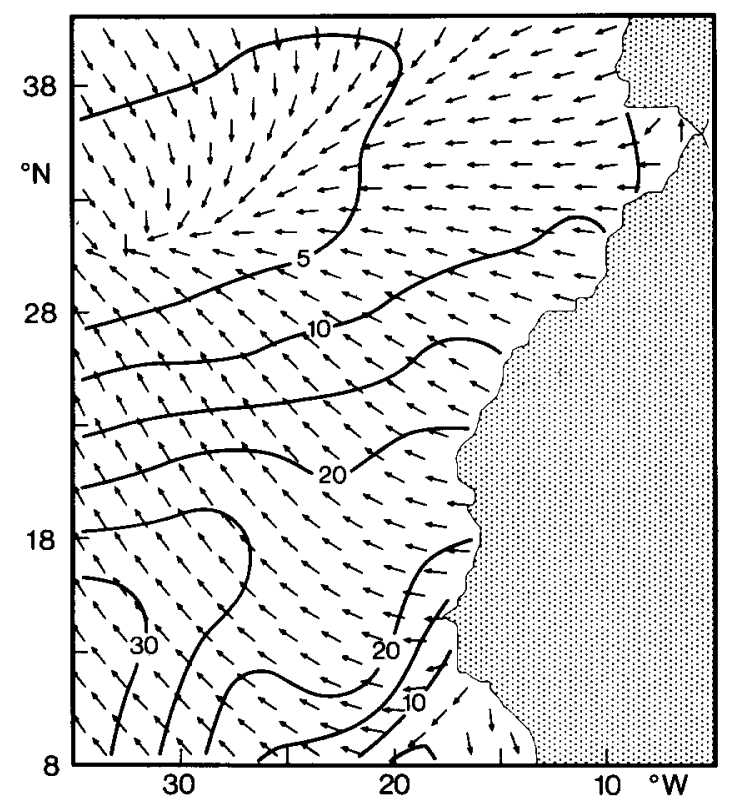

Fig. 2. Mean annual Ekman transport for 1941 to 1972. Vectors are plotted at every second grid point. The unit vector shows the direction. The isolines show the magnitude of the transport for one grid point. The contour interval is $5 \times 10^{-2} \mathrm{~Sv}\left(1 \mathrm{~Sv}=10^{6} \mathrm{~m}^{3} \mathrm{~s}^{-1}\right)$.

compensate for the high drag coefficients. The possibility of applying these results to the whole North Atlantic is still under investigation. The random error in the wind stress results, due to uncertainties in wind measurements and choice of bulk coefficients, is assumed to be $20 \%$.

For the present calculation we used the original parameterization from BUNKER (1976). The components of Ekman transport $E^{x}$ and $E^{y}$ were calculated as

$$
\begin{aligned}
& E^{x}=+\tau^{y} / f \\
& E^{y}=-\tau^{x} / f,
\end{aligned}
$$

where $\tau^{x}$ and $\tau^{y}$ are the components of wind stress and $f(=2 \Omega \sin \phi)$ is the Coriolis parameter. The integrated mean annual Ekman transport for each $1^{\circ}$ field $(111 \times 111 \times$ $\cos \phi \mathrm{km}^{2}$ ) is shown in Fig. 2. Prominent features are the eastern end of the subtropical convergence line (which separates the trade winds region from the area of prevailing westerlies) and the northeast trade winds zone, with Ekman transports directed mainly to the northwest. The 'fingerprint' of the Intertropical Convergence Zone can be seen near the coast south of Cape Verde $\left(15^{\circ} \mathrm{N}\right)$ with decreasing Ekman transport and conspicuous divergence patterns.

\section{AIR-SEA HEAT FLUX}

The air-sea heat flux (NET) can be computed as the residuum of the incoming shortwave radiation flux $(Q R)$, the net longwave radiation flux $(I R)$ and the turbulent fluxes of latent $(\mathrm{LH})$ and sensible heat $(\mathrm{SH})$ : 


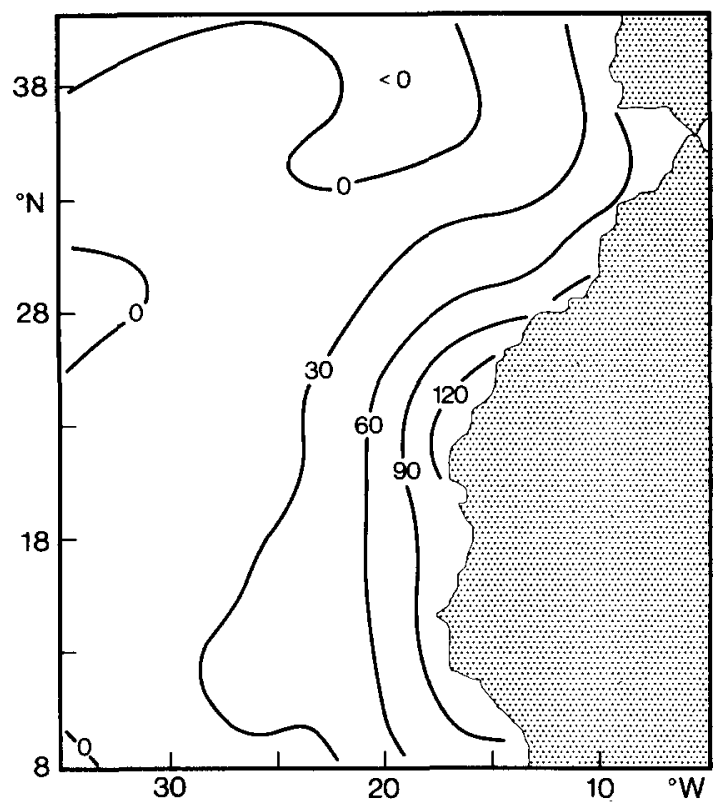

Fig. 3. Mean annual air-sea heat fluxes for 1941 to 1972 . The contour interval is $30 \mathrm{Wm}^{-2}$. Positive values indicate energy input to the ocean.

$$
Q R-I R-L H-S H=N E T .
$$

BUNKER (1976) calculated long-term monthly fluxes from averaged meteorological parameters using formulas of Budyko for $Q R$ and Berliand/Budyko for $I R$. Similar to his wind stress calculations, Bunker used the bulk equations with wind speed- and stabilitydependent Stanton and Dalton numbers for computing sensible and latent fluxes. A particular strength of Bunker's work is his use of the so-called 'individual' method: he computed the turbulent fluxes for each individual ship observation and averaged afterwards instead of computing fluxes from averaged meteorological parameters.

The picture of the annual air-sea heat fluxes (Fig. 3) in the eastern North Atlantic shows energy gain at the surface, except for two tongues with negative values at the northern and western edge of the area. Values larger than $90 \mathrm{Wm}^{-2}$ are confined to the nearshore upwelling region. The annual average value for the entire area is $27 \mathrm{Wm}^{-2}$. The annual cycle shows a change of the sign in the region west of $18^{\circ} \mathrm{W}$ (ISEMER and HASSE, 1986), the average for January is $-52 \mathrm{Wm}^{-2}$ but $88 \mathrm{Wm}^{-2}$ for July. With the total sea surface area of $8.2 \times 10^{12} \mathrm{~m}^{2}$, the integrated energy input is $0.22 \mathrm{PW}$. This area integral is computed from 85 independent subarea averages. The random error of each of the latter is assumed to be $50 \mathrm{Wm}^{-2}$, which leads to a mean error of the total area integral of $0.04 \mathrm{PW}$, if all errors are purely random.

\section{GEOSTROPHIC TRANSPORT}

In geostrophic computations using the density distribution, there is always the problem of transferring relative to absolute velocity. Although different methods exist, the 


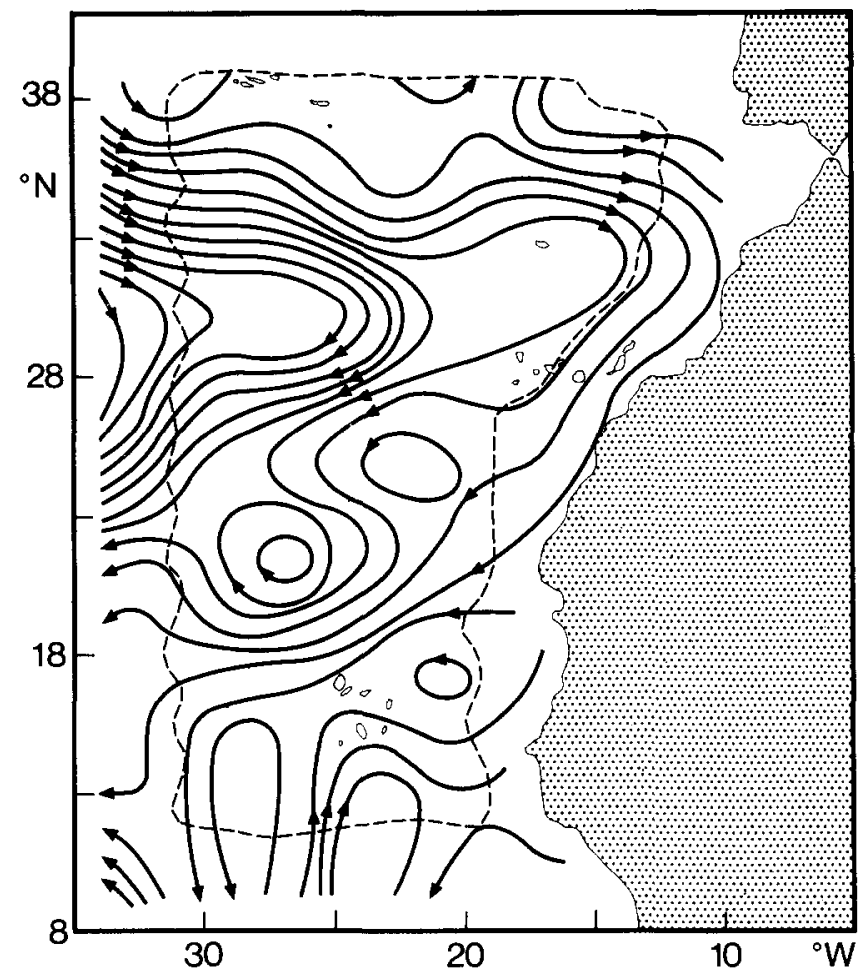

Fig. 4. Integrated volume transport $(0$ to $1000 \mathrm{~m})$ from mean density profiles. Each flow line represents $1 \mathrm{~Sv}$. The error field is $<1 \mathrm{~Sv}$ within the area outlined by dashed lines.

problem of computing absolute velocities is not yet solved. It would be unrealistic to expect that a permanent surface exists wherein the velocities are zero. But one can identify a low-velocity layer, which, when used as an integration reference, yields reasonable, accurate transport. We call this layer here the level of no motion. STRAmma (1984a) determined a level of no motion in the subtropical eastern North Atlantic using mean profiles produced from an edited data set of historic hydrographic data for all $3^{\circ} \times$ $3^{\circ}$ squares of the subtropical eastern North Atlantic. Defant (1941) suggested that the level of no motion be taken where the vertical gradient of the geopotential anomaly difference between two stations is zero or nearly zero. Stramma (1984a) combined Defant's method with information on the advection of water masses, identified by oxygen and salinity maxima and minima and a conservation of mass scheme first used by FiadeIRo and Veronis (1982). The chosen reference depth (the level of no motion) is located at $1500 \mathrm{~m}$ in the tropics and climbs to $1200 \mathrm{~m}$ in the subtropics (Fig. 6 of Stramma, 1984a). With this given reference depth, the absolute transport can be computed. If the reference level is replaced by $2000 \mathrm{~m}$ depth, there is a difference of $<12 \%$ in the 0 to $1000 \mathrm{~m}$ transport across a section. The total transport changes by $<5 \%$ when noise-simulating alterations are made to the mean temperature and salinity profiles. Therefore, the error for 0 to $1000 \mathrm{~m}$ transport is $15 \%$, caused by uncertainty in, the choice of a reference level and data noise.

Figure 4 presents the transport in the upper $1000 \mathrm{~m}$ depth of the subtropical eastern 
North Atlantic. These contours were prepared and smoothed with an objective analysis scheme developed by HILLER and KäSE (1983). As the correlation scale was not known, a value of $470 \mathrm{~km}$ was chosen arbitrarily, which is about 1.4 times the length between the mean profiles and is a scale larger than the eddy scale. The error variance was chosen to be $15 \%$ of the total variance. The error field computed with the objective analysis scheme shows error values lower than $1 \mathrm{~Sv}$ within the area outlined by dashed lines in Fig. 4 . The objective analysis scheme was used only in Fig. 4 to show the smoothed subtropical gyre. The calculations of geostrophic temperature fluxes were performed without smoothing.

The main inflow enters south of the Azores as a relatively narrow current, turns southward at about $33^{\circ} \mathrm{N}$ and then widens. Three current bands transport the water southward. The current bands are separated by Madeira and the Hyers and Meteor Seamounts near $30^{\circ} \mathrm{N}, 28^{\circ} \mathrm{W}$. North of the Cape Verde Islands, the current turns westward and forms the North Equatorial Current (NEC). The Portugal Current is seen in Fig. 4 as a relatively weak flow. The subtropical gyre transport for the upper $1000 \mathrm{~m}$ east of $35^{\circ} \mathrm{W}$ is $12 \mathrm{~Sv}$ or less. The historic data base for $3^{\circ} \times 3^{\circ}$ squares is too small to divide them by season.

Computations of geostrophic transport from the sea surface to the ocean bottom show much higher errors than for the 0 to $1000 \mathrm{~m}$ transport field. As Fomin (1964) showed, the error of the dynamic method increases linearly with depth. In addition, the velocities in the deep sea are small compared to velocities of the warm water sphere, and a bad choice of reference depth will have a greater influence on the deep-sea transport values. Transport calculations from the surface to the bottom show southward flow with high variability. The errors computed with the objective analysis scheme are always $>2.6 \mathrm{~Sv}$ for a correlation scale of $470 \mathrm{~km}$ and an error variance of $20 \%$. The total southward transport of the surface-to-bottom is weaker than the 0 to $1000 \mathrm{~m}$ transport field. With the high error boundary of $2.6 \mathrm{~Sv}$, it is not meaningful to present the surface-to-bottom flow field. With the geostrophic transport, the temperature flux due to geostrophic transport can be computed with the direct method.

The total temperature flux of the eastern North Atlantic is computed from the temperature flux due to Ekman transport and that due to geostrophic transport using equation (1). Because the data come from two sources, it is convenient to rewrite (1) as

$$
H=\iint \rho C_{p} \theta v_{\text {Ekman }} \mathrm{d} z \mathrm{~d} x+\iint \rho C_{p} \theta v_{\text {geostrophic }} \mathrm{d} z \mathrm{~d} x .
$$

The Ekman volume transport is computed from $\int\left(-\tau^{x} / f\right) \mathrm{d} x$. Following HaLL and BRYDEN (1982), an Ekman depth of $50 \mathrm{~m}$ was assumed (with Ekman velocities decreasing linearly from their surface value to zero at $50 \mathrm{~m}$ ) and a weighted average of temperature at the surface and $50 \mathrm{~m}, \bar{\theta}=\left(2 \theta_{0 \mathrm{~m}}+\theta_{50 \mathrm{~m}}\right) / 3$, was used to calculate the Ekman temperature flux as

$$
H_{\text {Ekman }}=\int\left(-\tau^{x} / f\right) \bar{\theta} C_{p} \rho \mathrm{d} x .
$$

The sea surface temperature (SST) was taken from the ssmo data set. The accuracy of these SSTs is not as good as that of the data from oceanographic ship measurements, but 


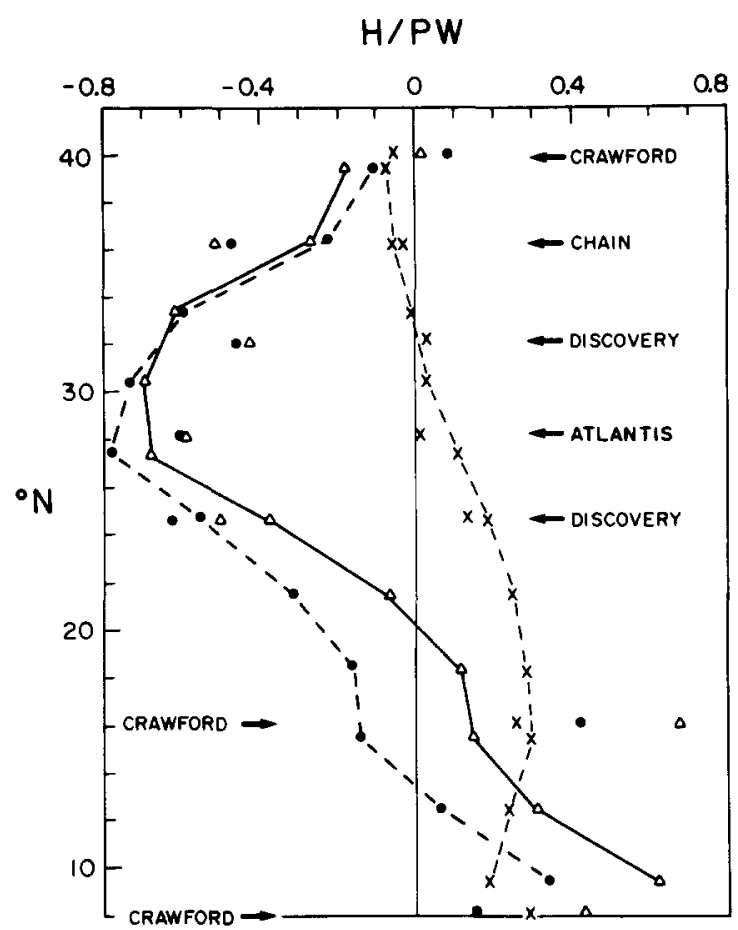

Fig. 5. Meridional temperature fluxes in the eastern North Atlantic between $35^{\circ} \mathrm{W}$ and the European and African coasts with geostrophic temperature fluxes for 0 to $1000 \mathrm{~m}$ depth. Crosses are the Ekman temperature fluxes, dots are the geostrophic temperature fluxes, and triangles are the sum of both components. Symbols connected with lines (dashed lines for the Ekman and geostrophic component, solid lines for the sum of both) are from mean annual values; single isolated symbols are results from the IGY sections. For the IGY sections the names of the ships which made the sections are given. Positive flux is to the north, negative to the south.

we used this data set because of the large number of observations compared to the data from oceanographic CTD stations and because SST is a weighted mean value for the year from monthly SST values weighted by the number of days in each month. The temperature at $50 \mathrm{~m}$ depth was taken from the mean profiles, which were not weighted because of the small number of observations. The density was taken as the density at $20 \mathrm{~m}$ depth. The results depend only slightly on density; therefore, the error due to the chosen density is negligible. For every $3^{\circ}$-square the Ekman temperature flux was computed and zonally summed. For comparison, temperature fluxes were also computed for IGY (International Geophysical Year) sections in the North Atlantic. These sections were made in different years and different months, but always in the winter half-year. The fluxes were zonally summed and are presented in Figs 5 and 6. To compute the Ekman transport at the time of the IGY cruises, the surface temperature was taken from the CTD data. The number of wind observations for the month of the cruise were so small that Ekman transport was computed from the mean monthly data for 1941 to 1972 (derived from the ssmo data). Data of IGY sections used, and the calculated Ekman and geostrophic temperature fluxes $(H)$ are given in Table 1. 


\section{$H / P W$}

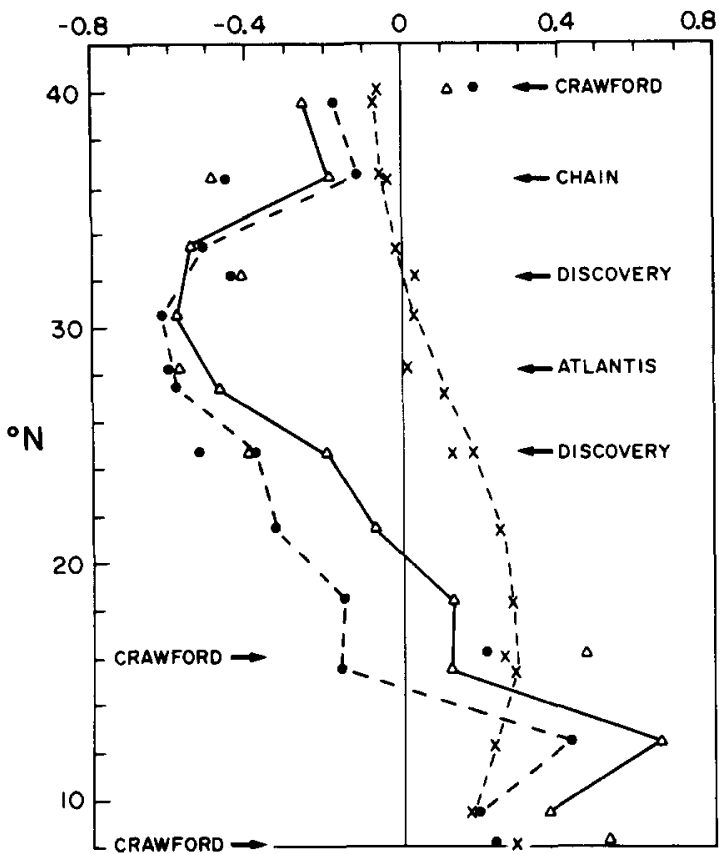

Fig. 6. Meridional temperature fluxes as in Fig. 5 but geostrophic temperature fluxes are from the sea surface to the ocean bottom.

Table 1. Ship, median, and date of the IGY sections used between $35^{\circ} \mathrm{W}$ and the African and European coasts, the meridional Ekman temperature flux $\left(\mathrm{H}_{E k m a n}\right)$, and the geostrophic temperature flux $\left(\mathrm{H}_{\text {geostrophic }}\right)$, both in $10^{12} \mathrm{~W} . \mathrm{H}_{\text {geosirophic }}$ is calculated for 0 to $1000 \mathrm{~m}$ depths and for $0 \mathrm{~m}$ depth to the ocean bottom. Negative flux is to the south; positive flux is to the north

\begin{tabular}{lccccc}
\hline Ship & & & \multicolumn{2}{c}{$H_{\text {geastrophic }}\left(\times 10^{12} \mathrm{~W}\right)$} \\
0 & ${ }^{\circ} \mathrm{N}$ & Date & $H_{\text {Ekman }}\left(\times 10^{2} \mathrm{~W}\right)$ & $0-1000 \mathrm{mottom}$ \\
\hline Crawford & $40^{\circ} 15^{\prime}$ & October, 1957 & -57 & 85 & 190 \\
Chain & $36^{\circ} 15^{\prime}$ & May, 1959 & -39 & -475 & -452 \\
Discovery & $32^{\circ} 15^{\prime}$ & December, 1957 & 28 & -454 & -441 \\
Atlantis & $28^{\circ} 15^{\prime}$ & February, 1959 & 7 & -603 & -590 \\
Discovery & $24^{\circ} 30^{\prime}$ & October, 1957 & 130 & -629 & -525 \\
Crawford & $16^{\circ} 15^{\prime}$ & November, 1957 & 252 & 422 & 210 \\
Crawford & $8^{\circ} 15^{\prime}$ & May, 1957 & 296 & 162 & 231 \\
\hline
\end{tabular}

\section{ANALYSIS OFERRORS}

The major source of error in the derived values is the geostrophic transport at greater depths because the error increases linearly with depth (Fomin, 1964). A comparison of 
Table 2. Errors in meridional geostrophic temperature flux $\left(\mathrm{H}_{\text {geesstrophic }}\right.$ in $\left.10^{12} \mathrm{~W}\right)$ from mean profiles along $24^{\circ} 30 \mathrm{iv}$ between $35^{\circ} \mathrm{W}$ and the African coast. R.S. is the reference depth between 1230 and $1340 \mathrm{~m}$ depth and $\Delta \mathrm{H}_{\text {geossrophic }}=\mathrm{H}_{\text {geossrophic }}\left(R . S\right.$. noise) $-\mathrm{H}_{\text {gersstrephic }}(R . S$.). Negative flux is to the south; positive flux is to the north

(a) Errors due to data noise

\begin{tabular}{lcrcr} 
Reference depth & \multicolumn{2}{c}{$0-1000 \mathrm{~m} \mathrm{depth}$} & \multicolumn{2}{c}{$0 \mathrm{~m}-$ ocean bottom } \\
& $H_{\text {geestrophic }}$ & $\Delta H_{\text {gcostrophic }}$ & $H_{\text {gcostrophic }}$ & $\Delta H_{\text {gensistrophic }}$ \\
\hline R.S. & -554 & & -384 & \\
R.S. noise I & -550 & 4 & -331 & 53 \\
R.S. noise II & -511 & 43 & -319 & 65 \\
R.S. noise III & -546 & 8 & -378 & 6 \\
\hline
\end{tabular}

(b) Errors due to reference depth

\begin{tabular}{lcccc} 
Reference depth (m) & \multicolumn{2}{c}{$0-1000 \mathrm{~m}$ depth } & \multicolumn{2}{c}{$0 \mathrm{~m}-$ ocean bottom } \\
& $H_{\text {geostrophic }}$ & $\%$ R.S. & $H_{\text {genstrophic }}$ & $\%$ R.S. \\
\hline 1000 & -549 & 99 & -359 & 93 \\
1500 & -637 & 115 & -550 & 143 \\
1700 & -662 & 120 & -604 & 157 \\
\hline
\end{tabular}

the 0 to $1000 \mathrm{~m}$ and surface to bottom heat fluxes for the IGY sections (Table 1) shows slightly larger southward (negative) fluxes for the upper $1000 \mathrm{~m}$ between $36^{\circ} 15^{\prime} \mathrm{N}$ and $24^{\circ} 30^{\prime} \mathrm{N}$. This difference becomes larger for the geostrophic temperature fluxes from the mean profiles (Figs 5 and 6). There is an additional uncertainty in computing a mean profile from profiles between 1910 and 1972.

Table 2 shows the errors due to data noise (Table 2a) and to the choice of reference depth (Table $2 \mathrm{~b}$ ) for the meridional geostrophic temperature flux along $24^{\circ} 30^{\prime} \mathrm{N}$ between $35^{\circ} \mathrm{N}$ and the African coast from mean profiles for the depth ranges 0 to $1000 \mathrm{~m}$ and $0 \mathrm{~m}$ to bottom. At $24^{\circ} 30^{\prime} \mathrm{N}$ the decrease in southward (negative) temperature fluxes from 0 to $1000 \mathrm{~m}$ depth to $0 \mathrm{~m}$ to bottom is large. The temperature flux is computed with a reference depth of 1230 to $1340 \mathrm{~m}$ from Stramma (1984a). Following Fiadeiro and VERONIS (1982), typical instrument precisions of $0.02^{\circ} \mathrm{C}, 0.005 \%$, and $0.5 \%$ for temperature, salinity, and depth, respectively, were multiplied by randomly selected numbers between -1 and +1 and then added to the mean profiles. The altered profiles were then used to compute the geostrophic temperature fluxes. Three sets of data with noise were produced (noise I, II and III). The fluxes of these data sets and the difference from the data without noise are shown in Table 2a. While the differences for the temperature flux with noise in these three data sets are $<9 \%$ for the 0 to $1000 \mathrm{~m}$ depth, the error due to noise increases to $17 \%$ for the surface-to-bottom layer.

The influence of the chosen reference depth is presented in Table $2 \mathrm{~b}$. Changing the reference depth (which is between 1230 and $1340 \mathrm{~m}$ in this section) to $1500 \mathrm{~m}$ increases the temperature flux in the top $1000 \mathrm{~m}$ by $15 \%$, while the flux for the surface-to-bottom range increases by $43 \%$. HALL and BRYDEN (1982) and RoEMmich (1983) computed the zero crossing of the north-south velocity at about $1200 \mathrm{~m}$ depth, with different computation schemes at this location. Thus the error due to the reference depth should be less than the increase for $1500 \mathrm{~m}$ depth. From these computations and from the geostrophic transport computations (STRAmma, 1984a), the errors in the geostrophic temperature flux due to the geostrophic method, data noise, and the reference depth are expected to 
be 10 to $15 \%$ for the 0 to $1000 \mathrm{~m}$ depth layer and up to $50 \%$ for the surface-to-bottom layer. As mentioned earlier, random errors in Ekman temperature flux calculations caused by uncertainties in the wind stress could be as much as $20 \%$. HALL and BRYDEN (1982) investigated the error of the eddy temperature flux and found that it could be as much as $25 \%$ of the total. We believe this error should be a larger problem in the western Atlantic and smaller in the eastern Atlantic. For the mean fluxes this error can be reduced by deriving mean profiles from all profiles in $3^{\circ} \times 3^{\circ}$ squares.

RESULTS

The mean annual meridional temperature fluxes are given for the top $1000 \mathrm{~m}$ of the ocean in Fig. 5. This depth includes the warm water sphere with the wind-driven southward flow of the subtropical gyre east of $35^{\circ} \mathrm{W}$. Assuming isopycnal motion, a density surface should be used as the lower boundary, but at $1000 \mathrm{~m}$ depth the differences in the heat flux computations are expected to be small because the velocities at that depth are low and the slope of isopycnal surfaces are small. In the geostrophic temperature flux, the subtropical gyre shown in Fig. 4 dominates. Low southward temperature flux is found at $39^{\circ} 30^{\prime} \mathrm{N}$, where the transport of the Portugal Current is small. The largest geostrophic temperature flux is found at $27^{\circ} 30^{\prime} \mathrm{N}$, where the geostrophic transport is also at a maximum, $12 \mathrm{~Sv}$. South of the NEC the southward heat flux is low and changes to a geostrophic northward temperature flux in the tropics south of $13^{\circ} \mathrm{N}$. The annual Ekman temperature flux north of $32^{\circ} \mathrm{N}$ is also to the south and contributes to the southward geostrophic component. At $39^{\circ} 30^{\prime} \mathrm{N}$ the Ekman flux is almost as large as the geostropic flux, but between $36^{\circ} 30^{\prime} \mathrm{N}$ and $24^{\circ} 30^{\prime} \mathrm{N}$ the Ekman flux is small compared to the large geostrophic flux due to the subtropical gyre. South of $32^{\circ} \mathrm{N}$ the Ekman flux is to the north and weakens the geostrophic component. Therefore, the maximum total southward flux appears at $30^{\circ} 30^{\prime} \mathrm{N}$ and not at $27^{\circ} 30^{\prime} \mathrm{N}$, where the geostrophic component is largest. South of $24^{\circ} 30^{\prime} \mathrm{N}$ the Ekman temperature flux is of the same order as the geostrophic flux. Although the geostrophic flux between 13 and $20^{\circ} \mathrm{N}$ is southward, the total temperature flux is northward because the Ekman flux dominates. Between 8 and $13^{\circ} \mathrm{N}$ both temperature flux components are northward and the total temperature flux to the north is large.

In most cases the difference from the mean annual Ekman temperature flux is small for the months of the IGY sections (Fig. 5). At the Atlantis section at $28^{\circ} 15^{\prime} \mathrm{N}$ the difference is larger and the value for February is almost zero. The subtropical convergence has its mean annual location at $32^{\circ} \mathrm{N}$ (Fig. 2), but shifts in winter to the south. In February its location is $28^{\circ} \mathrm{N}$. Also in the IGY sections the geostrophic temperature flux dominates in the subtropical gyre (Fig. 5). At the Crawford section at $40^{\circ} 15^{\prime} \mathrm{N}$ the geostrophic temperature flux was to the north. The reason is a northward transport northwest of the Azores near the Mid-Atlantic Ridge, which dominates the weak Portugal Current. The same relationship exists for the annual mean values (Fig. 4), but here the Portugal Current dominates. This latitude of weak southward or northward transport in the eastern Atlantic was found by WUNSCH (1984) from an ocean circulation model to be the latitude of maximum possible annual-mean poleward heat flux in the Atlantic. The Chain section at $36^{\circ} 15^{\prime} \mathrm{N}$ was in the area of the strong eastward current. A small shift in the flow axis may cause large differences in the geostrophic temperature flux; therefore, the large 
difference from the mean value seen in Fig. 5 seems possible. The Discovery section at $32^{\circ} 15^{\prime} \mathrm{N}$ and the Atlantis section at $28^{\circ} 15^{\prime} \mathrm{N}$ were made in December and February and show smaller temperature fluxes, while the Discovery section at $24^{\circ} 30^{\prime} \mathrm{N}$ was done in October and shows higher temperature fluxes. The differences are higher than the expected error of 10 to $15 \%$ for this depth range. This is an indication that the geostrophic temperature fluxes have a seasonal signal with lower values for the summerautumn period. The Crawford section at $16^{\circ} 15^{\prime} \mathrm{N}$ in November 1957 shows a large northward temperature flux (Table 1), while the mean geostrophic flux is to the south. OORT and VONDER HAAR (1976) found a maximum heat transport to the north for the zonal mean between 10 and $20^{\circ} \mathrm{N}$, which changes sign from July to September and is then southward transport. Our findings are consistent with their findings from an indirect method with a different data base. The area south of the NEC has large seasonal variability and the geostrophic temperature flux changes from a southward to a northward flux.

In Fig. 6 the results are given for geostrophic transport from the surface to the bottom. Most of the features described above for Fig. 5 may be also seen in this figure. The geostrophic temperature fluxes are in general smaller than the 0 to $1000 \mathrm{~m}$ depth fluxes. This seems very unlikely, but we must mention the large errors, which could be up to $50 \%$. Figure 6 is given for completeness. The main temperature fluxes are expected in the warm water sphere, where the error is small.

Comparisons with the results of single transatlantic sections are difficult, because only a part of the Atlantic is investigated in this paper. With a different direct method, HaLL and BRYDEN (1982) computed the heat transport for the Discovery section along $24^{\circ} 30^{\prime} \mathrm{N}$. Between the Bahamas and Africa they found a geostrophic temperature flux of $1.58 \mathrm{PW}$ to the south. For the same IGY section we find a geostrophic flux of $0.52 \mathrm{PW}$ to the south between $35^{\circ} \mathrm{W}$ and the African coast. The value from the mean profiles is $0.38 \mathrm{PW}$ for the surface to bottom but $0.55 \mathrm{PW}$ for the 0 to $1000 \mathrm{~m}$ depth. At greater depths an unrealistically large northward volume flux occurs, caused by the error from the mean profiles and the dynamic method. A temperature flux of $0.52 \mathrm{PW}$ to the south from the IGY section and the mean 0 to $1000 \mathrm{~m}$ flux related to a volume transport of $10 \mathrm{~Sv}$ seems to be reasonable. HALL and BRYDEN (1982) computed their southward temperature flux of $1.58 \mathrm{PW}$ with a geostrophic volume transport of $29.5 \mathrm{~Sv}$. The eastern North Atlantic east of $35^{\circ} \mathrm{W}$ therefore transports one-third of the geostrophic volume and temperature flux, which agrees well with the values of Hall and Bryden. For the Ekman flux they used a northward temperature flux of $0.53 \mathrm{PW}$ caused by Ekman transport of $5 \mathrm{~Sv}$. Our values for the eastern Atlantic east of $35^{\circ} \mathrm{W}$ are $0.13 \mathrm{PW}$ with $1.2 \mathrm{~Sv}$ in October and $0.18 \mathrm{PW}$ with $1.8 \mathrm{~Sv}$ from the mean values. Our results for the eastern North Atlantic from the Discovery section at $24^{\circ} 30^{\prime} \mathrm{N}$ and from the mean profiles at $24^{\circ} \mathrm{N}$ are in good agreement to the transatlantic computations by HALL and BRYDEN (1982).

\section{EAST ATLANTIC HEAT GAIN}

As mentioned earlier, the southward flows in the east of the subtropical gyres are areas of heat gain by the ocean. Considering the temperature fluxes across all three of the open faces of the box, we calculate the mean heat flux divergence for the area investigated. The net volume transport has to be zero. We consider only the upper $1000 \mathrm{~m}$, since it is 
believed that the net transport across deep isopycnal surfaces is small within the bounded region. Only layers which are directly exposed to the atmosphere will be important in our regional balance. Therefore, deep flows do not contribute significantly to the heat flux divergence. At $33^{\circ} 30^{\prime} \mathrm{W}$ the geostrophic temperature flux from the mean profiles is $0.75 \mathrm{PW}$ to the east between $27^{\circ} 30^{\prime} \mathrm{N}$ and $39^{\circ} 30^{\prime} \mathrm{N}$ and $1.28 \mathrm{PW}$ to the west between $9^{\circ} 30^{\prime} \mathrm{N}$ and $27^{\circ} 30^{\prime} \mathrm{N}$. The Ekman temperature flux at $33^{\circ} 30^{\prime}$ is $0.02 \mathrm{PW}$ to the east north of $32^{\circ} \mathrm{N}$ and $0.27 \mathrm{PW}$ to the west south of $32^{\circ} \mathrm{N}$. For these zonal temperature fluxes the geostrophic temperature flux is large compared to the Ekman temperature flux and is also large compared to the meridional geostrophic temperature fluxes east of $35^{\circ} \mathrm{W}$. To reach zero volume flux the geostrophic flow to the Mediterranean Sea at $9^{\circ} 30^{\prime} \mathrm{W}$ had to be included with a geostrophic temperature flux of $0.15 \mathrm{PW}$ to the east and an Ekman temperature flux to the west of $0.03 \mathrm{PW}$. The total balance for the eastern Atlantic is a heat flux deficit of $0.19 \mathrm{PW}$, which has to be compensated by a heat gain of the ocean of $0.19 \mathrm{PW}$ from the atmosphere. This result is close to the $0.22 \mathrm{PW}$ computed from Bunker's data.

BEHRINGER and STOMMEL (1981) computed the rate of heat gain in the tropical Atlantic from subsurface oceanographic data and wind stress data. Their annual mean rate implies a net heat loss over much of the tropical ocean. A heat gain occurs only near the African coast between 15 and $30^{\circ} \mathrm{N}$ east of $20^{\circ} \mathrm{W}$ with a maximum value of $14 \mathrm{Wm}^{-2}$, while we find a mean value for the east Atlantic investigated here of $27 \mathrm{Wm}^{-2}$ from Bunker's data. Therefore, our heat gain result from the direct method is closer to the result of BUNKER (1976) computed from bulk equations than to those of BEHRINGER and Stommel (1981), who used subsurface oceanic data and wind stress data.

The error for the heat flux divergence should be less than the errors given for single sections and for the reference depth $(0.04$ to $0.08 \mathrm{PW})$, because a part of the change in temperature flux due to a change in the volume transport has to be compensated by a change in temperature and volume transport of opposite sign at another boundary of the area to fulfill the required zero volume transport. Further, the $1000 \mathrm{~m}$ depth is far below density surfaces exposed to the atmosphere in the region investigated here; therefore, the heat gain results for a depth or a density surface as lower boundary should be quite similar.

\section{DISCUSSION}

This investigation has treated only a part of the Atlantic Ocean; therefore, no meridional heat fluxes have been computed for the amount of heat transported in the Atlantic Ocean. Contrary to heat flux computations on single sections, here one can see changes in the meridional temperature fluxes at different latitudes, the influence of the subtropical gyre, and the role of Ekman temperature fluxes. The temperature fluxes to the south in the area of the subtropical gyre are dominated by the geostrophic temperature flux in the eastern Atlantic east of $35^{\circ} \mathrm{W}$, where the Ekman temperature flux is small and changes direction. The Ekman temperature flux plays a major role east of the Azores where it is as large as the small geostrophic southward flow caused by the Portugal Current, and in the tropics where a large northward Ekman flux adds to a northward geostrophic temperature flux. The change from a total southward temperature flux in the subtropics to a northward flux in the tropics occurs at $20^{\circ} \mathrm{N}$ in the eastern 
Atlantic. The comparison of the temperature fluxes from mean annual profiles and Ekman transports with those of different CTD sections done in the winter half-year show that the seasonal influence on the Ekman temperature fluxes is low, while a seasonal signal in the geostrophic temperature fluxes appears, which is greater than the expected error for the 0 to $1000 \mathrm{~m}$ depth layer. This layer gives reliable results. The warm water sphere gives the largest contribution to the temperature fluxes because the wind-driven subtropical gyre has large flow velocities compared to deep-sea velocities and the contribution to the temperature flux is larger in the warm water sphere due to higher temperatures than those at greater depths. The subtropical gyre is a permanent feature (STramma, 1984b); therefore, mean profiles can represent a mean flow field. For the investigation of the seasonal influence, more information from further east-west CTD sections is necessary to check the results on seasonal variability. Errors for the surface to bottom temperature fluxes are large. For completeness these results have been presented to show that the findings are also visible for this layer. The comparison with the results of HALL and BRYDEN (1982) shows good agreement with their computations at $24^{\circ} 30^{\prime} \mathrm{N}$. The heat flux divergence leads to a value of $0.19 \mathrm{PW}$ of ocean heat gain from the atmosphere in the area of the eastern North Atlantic covered in this study. This investigation gives at least an insight into changes in meridional temperature fluxes at different latitudes and encourages further investigations.

Acknowledgements-This work was supported by the Deutsche Forschungsgemeinschaft, Bonn, F.R.G., and done at the Institut für Meereskunde, Kiel for the Sonderforschungsbereich 133. Some final computations and processing of the text were done at the University of Rhode Island, U.S.A., with support from the U.S. Office of Naval Research (grant N00014-81-C-0062). We would like to thank G. Siedler for helpful discussions and the anonymous reviewers for helpful comments on the manuscript.

REFERENCES

BeHRinger D. and H. STOMmel (1981) Annual heat gain of the tropical Atlantic computed from subsurface ocean data. Journal of Physical Oceanography, 11, 1393-1397.

Bryan K. (1983) Poleward heat transport by the oceans. Reviews of Geophysics and Space Physics, 21, $1131-1137$.

Bunker A. F. (1976) Computations of surface energy flux and annual air-sea interaction cycles of the North Atlantic Ocean. Monthly Weather Review, 104, 1122-1140.

Defant A. (1941) Die absolute Topographie des physikalischen Meeresniveaus und der Druckflächen, sowie die Wasserbewegungen im Atlantischen Ozean. Deutsche Atlantische Expedition "Meteor" 1925-1927, 2. 191-260.

Fiadeiro M. E. and G. Veronis (1982) On the determination of absolute velocities in the ocean. Journal of Marine Research, 40, Suppl., 159-192.

Fomin L. M. (1964) The dynamical method in oceanography. Elsevier Oceanographic Series, $212 \mathrm{pp}$

HAll M. M. and H. L. BRYDEN (1982) Direct estimates and mechanisms of ocean heat transport. Deep-Sea Research, 29, 339-359.

Hasse L., M. Grunewald, J. Wucknitz, M. Dunckel and D. Schriever (1978) Profile derived turbulent fluxes in the surface layer under disturbed and undisturbed conditions during GATE. "Meteor" Forschungsergebnisse $B, 13,24-40$.

HASTENRATH S. (1982) On meridional heat transport in the world ocean. Journal of Physical Oceanography, $12,922-927$.

HILLER W. and R. H. KÄSE (1983) Objective analysis of the hydrographic data sets from mesoscale surveys. Berichte aus dem Institut für Meereskunde, Kiel, 116, $78 \mathrm{pp}$.

ISEMER H.-J. and L. HASSE (1985) The Bunker climate atlas of the North Atlantic Ocean, Vol. 1, Observations. Springer Verlag, Berlin, $218 \mathrm{pp}$. 
ISEMER H.-J. and L. HASSE (1986) The Bunker climate atlas of the North Atlantic Ocean, Vol. 2, Air-sea interactions. Springer Verlag, Berlin (in press).

KAUFELD L. (1981) The development of a new Beaufort equivalent scale. Meteorologische Rundschau, 34, $17-23$.

LAMB P. J. and A. F. BUNKER (1982) The annual march of the heat budget of the North and Tropical Atlantic Oceans. Journal of Physical Oceanography, 12, 1388-1410.

OORT A. H. and T. H. Vonder HAAR (1976) On the observed annual cycle in the ocean-atmosphere heat balance over the northern hemisphere. Journal of Physical Oceanography, 6, 781-800.

Roemmich D. (1980) Estimation of meridional heat flux in the North Atlantic by inverse method. Journal of Physical Oceanography, 10, 1972-1983.

RoEMmich D. (1983) The balance of geostrophic and Ekman transports in the tropical Atlantic Ocean. Journal of Physical Oceanography, 13, 1534-1539.

SiEdler G. and L. Stramma (1983) The applicability of the T/S method to geopotential anomaly computations in the North-East Atlantic. Oceanologica Acta, 6, 167-172.

SмITH S. D. (1980) Wind stress and heat flux over the ocean in gale force winds. Journal of Physical Oceanography, 10, 709-726.

SMITH S. D. and F. DOBSON (1984) The heat budget at ocean weather station bravo. Atmosphere-Ocean, 22, $1-22$.

Stramma L. (1984a) Geostrophic transport in the Warm Water Sphere of the eastern subtropical North Atlantic. Journal of Marine Research, 42, 537-558.

Stramma L. (1984b) Potential vorticity and volume transport in the eastern North Atlantic from two long CTD sections. Deutsche Hydrographische Zeitschrift, 37, 147-155.

VONDER HARR T. H. and A. H. OORT (1973) New estimate of annual poleward energy transport by Northern Hemisphere Oceans. Journal of Physical Oceanography, 3, 169-172.

Wunsch C. (1984) An eclectic Atlantic Ocean circulation model. Part I: the meridional flux of heat. Journal of Physical Oceanography, 14, 1712-1733. 